\title{
РАЗРАБОТКА ЭФФЕКТИВНОЙ МЕТОДИКИ БЮДЖЕТНОГО МЕНЕДЖМЕНТА
}

Реализация финансово-бюджетной политики государства имеет иеель соииально-экономическое развитие, обеспечение безопасности страны, повышение благосостояния населения. В данной статье рассмотрена методика агрегированного распределения расходов бюджета на следуюшие группы, в зависимости от сферы деятельности: расходы на развитие человеческого капитала, на инновационное стимулирование экономики, на управление государством. Для количественного исследования такого влияния нами составлены три модели множественной регрессии, рассматривающие влияние на ВВП расходов каждой из рассмотренных выше групп. Данными для расчета являются статистические данные Республики Казахстан за 2013-2019 гг. В качестве инструмента проведения эконометрического моделирования использована программа Stata14.

Полученные результаты свидетельствует о возрастающей роли затрат бюджета на развитие человеческого капитала в формировании ВВП.

Для повышения эффективности использования государственных финансов предлагаем использовать иелостную систему открытости деятельности государственных органов на базе информационной системы управления общественными финансами «Электронный бюджет», применение которой повысит достоверность учета обязательств и скорости формирования отчетности, прекратит постоянную сверку информации между органами казначейства и бюджетополучателями, обеспечит прозрачность бюджетных расходов и создаст систему непрерывного автоматического казначейского контроля на всех этапах исполнения бюджета.

Ключевые слова: расходы бюджета, человеческий капитал, множественная регрессия, стимулирование экономики, эконометрическое моделирование, инновации, планирование, органы казначейства, достоверность, отчетность

Keywords: budget expenditures, human capital, multiple regression, economic stimulation, econometric modeling, innovation, planning, treasury bodies, reliability, reporting

Кілтсөздер: бюджетшывыстары, адамикапитал, көптегенрегрессия, экономиканыылталандыру, эконометрикалықмодельдеу, инновациялар, жоспарлау, қазынашылыққргандары, анықтық, есептілік

JEL classification: H50

Введение. Актуальность темы статьи обусловлена необходимостью эффективной организации бюджетного менеджмента, необходимой для развития экономики Республики Казахстан в виде более регулируемого процесса.

Целью бюджетного менеджмента является реализация финансово-бюджетной политики государства с целью социально-экономического развития, обеспечения безопасности страны, повышения благосостояния населения.

Для достижения цели исследования поставлены и решены следующие задачи:

- проведен анализ научной литературы по рассматриваемому вопросу;

- рассмотрено экономическое содержание и структура бюджетного менеджмента;
- проведен корреляционный анализ зависимости ВВП от исполнения затрат государственного бюджета Республики Казахстан по расходам, сгруппированным по различным сферам деятельности.

В условиях рыночных отношений для оценки эффективности использования бюджетных средств подразумевает совершенствование методов планирования и финансирования бюджетных расходов.

Разработка эффективной методики управления бюджетом необходима в связи с проведением в Республике Казахстан бюджетной реформы, предполагающей постепенный переход от сметного планирования и финансирования бюджетных расходов к бюджетному планированию, 


\section{Каржы жеәне есеп / Финансы и учет}

ориентированному на достижение конечных общественно значимых и измеримых результатов. Необходимо обеспечение прозрачности бюджетных расходов и создание системы непрерывного контроля на всех этапах исполнения бюджета.

Бюджетный менеджмент основан на совокупности эффективных действий, приемов, методов и способов, которые осуществляют органы государственной власти, органы местного самоуправления и другие хозяйствующие субъекты по управлению бюджетными отношениями, возникающими при образовании, распределении, перераспределении и использовании государственных бюджетных средств.

Эффективное управление бюджетными ресурсами Республики Казахстан затрудняется из-за большого количества программ, ответственность за реализацию которых возложена на различные государственные органы, в связи с чем в статье рассматривается использованиесистемы «Электронный бюджет».

Методами исследования, применяемыми при написании данной статьи, являются: анализ научной литературы, синтез, обобщение, методы статистического и регрессивно-коррекционного анализа.

Обзор литературы. Многие экономисты считают, что при формировании бюджетной политики необходимо найти оптимальное соотношение между видами расходов государственного бюджета.

Профессор Искакова З.Д. считает недостатком является использование в Казахстане ограниченного количества инструментов для критической оценки расходов по бюджетной программе [1, с. 41].

Отечественные ученые Р.К. Сабирова, Д. Косаев, У. Куанышев отмечают, что в отношении эффективности использования государственных ресурсов, свыше 30\% нарушений допущены из-за несоблюдения бухгалтерского учета, Бюджетного кодекса, более 40\% нарушений допущены из-за несоблюдения отраслевого законодательства. По итогам аудиторских мероприятий отмечена неэффективная реализация бюджетных программ, связанная, как правило, с некачественным их планированием, что в последующем негативно влияет на их исполнение, приводит к неосвоению средств. Многочисленные нарушения выявле- ны при проведении аудиторских мероприятий в регионах, в том числе и нарушения, допускаемые при реализации инвестиционных проектов, программных документов [2, с. 65].

Российский ученый А.С. Сухарев отмечает, что постатейное сопоставление запланированных и реальных расходов не даст точной оценки эффективности бюджетных расходов. Кроме того, на основе такой оценки невозможно определить, следует ли увеличить финансирование или снизить его по каким-то статьям и на какую величину. Ученый предлагает выделить в агрегированном виде следующие группы расходов бюджета (по сферам):

- расходы на развитие человеческого капитала;

- расходы на инновационное стимулирование экономики;

- расходы на управление государством (включая расходы на обеспечение внутренней и внешней безопасности) [3, с. 23].

В связи с противоречивостью научной дискуссии, нами при помощи эконометрического моделирования определено влияние зависимости ВВП от расходов на инновационное стимулирование экономики.

Основная часть. Среди главных задач бюджетного менеджмента в Республике Казахстан следует отметить следующие:

- мобилизацию государственных бюджетных ресурсов;

- бесперебойное финансирование затрат для осуществления задач государства и органов местного самоуправления;

- повышение качества управления за использованием государственных бюджетных и внебюджетных средств;

- процесс усиления государственного финансового контроля [4].

Российский ученый А.С. Сухарев отмечает, что постатейное сопоставление запланированных и реальных расходов не даст точной оценки эффективностибюджетных расходов. Кроме того, на основе такой оценки невозможно определить, следует ли увеличить финансирование илиснизить его по каким-то статьям и на какую величину. Ученый предлагает выделить в агрегированном виде следующие группы расходов бюджета (по сферам):

- расходы на развитие человеческого капитала; 


\section{Каржы және есеп / Финансы и учет}

- расходы на инновационное стимулирование экономики;

- расходы на управление государством (включая расходы на обеспечение внутренней и внешней безопасности).

До проведения этапа отбора и формирова- ния однотипных групп расходов, необходимо определить основные признаки (принципы) такого отбора, позволяющие в дальнейшем оценивать и эффективность бюджетных расходов (по каждому направлению) (рис. 1).



Рисунок 1. Классификация бюджетных расходов А.С. Сухарева*

* Составлен автором по [3]

На показатель ВВП Республики Казахстан, безусловно, оказывают влияние множество факторов, в том числе затраты государственного бюджета.

Начнем регрессивно-коррекционный анализ с группы расходов бюджета на развитие человеческого капитала.

Результативный показатель: У - величина ВВП Республики Казахстан, млрд тг.

Факторы, зависящие от результативного показателя:
X1 - расходы на образование, млрд тг.;

X2 - расходы бюджета на здравоохранение, млн тг.,

X3 - расходы на социальное обеспечение населения, млн тг.;

X4-расходы на культуру, спорт и туризм, млн тг.

Для составления модели используем статистические данные за 2013-2019 гг. [6].

Для расчета параметров регрессии построим расчетную таблицу 1 .

Матрица задачи статистического анализа *

\begin{tabular}{|c|r|r|r|r|r|r|r|}
\hline Показатель & \multicolumn{1}{|c|}{2013 г } & \multicolumn{1}{|c|}{2014 г } & \multicolumn{1}{|c|}{2015 г } & \multicolumn{1}{|c|}{2016 г } & \multicolumn{1}{|c|}{2017 г } & \multicolumn{1}{c|}{2018 г } & \multicolumn{1}{c|}{2019 г } \\
\hline $\mathrm{V}$ & 35999 & 39676 & 40884 & 46971 & 54378 & 61819 & 64600 \\
\hline $\mathrm{X} 1$ & 1237421 & 1358669 & 1364737 & 1669398 & 1843243 & 1948477 & 2121000 \\
\hline $\mathrm{X} 2$ & 795092 & 856222 & 863899 & 1039576 & 1128316 & 1173313 & 1431442 \\
\hline $\mathrm{X} 3$ & 1359664 & 1548638 & 1713451 & 1977315 & 2302330 & 2751354 & 3301625 \\
\hline $\mathrm{X} 4$ & 258431 & 297795 & 293775 & 326653 & 398540 & 449291 & 516685 \\
\hline
\end{tabular}

Таблица 1

* Составлена автором по [6]

Одна из важнейших задач статистического моделирования - выявление количественной меры влияния комплекса факторов на результативный показатель. Проведем корреляционный анализ зависимости ВВП от исполнения затрат государственного бюджета Республики Казахстан по расходам, связанным с развитием человеческого капитала. Расчеты производим с помощью программы Stata14. Все коэффи- циенты являются значимыми на 5\% уровне значимости, модель является значимой в целом, а свободный член не является статистически значимым и надежным.

В результате расчетов было получено уравнение множественной регрессии:

$$
\mathrm{y}=0,03 \mathrm{x} 1-0,04 \mathrm{x} 2+0,01 \mathrm{x} 3+0,04 \mathrm{x} 4
$$

Следовательно, в рассматриваемой нами 


\section{Қаржы жсәне есеп / Финансы и учет}

модели наибольшее влияние на результативный показатель (У) оказывает фактор Х4 - расходы на культуру, спорт и туризм. При увеличении затрат бюджета на культуру, спорт, туризм на 1 млн тенге, ВВП увеличится на 0,04 млрд тенге.

Аналогично проведем интерпретацию других факторов, влияющих на результативный показатель:

- при увеличении расходов на образование на 1 млн тенге, ВВП увеличится на 0,03 млрд тенге;

- при увеличении расходов на здравоохранение на 1 млн тенге, ВВП уменьшится на 0,04 млрд тенге. Такой парадоксальный результат можно объяснить тем, что эффект от вложений бюджетных средств в здравоохранение, будет способствовать росту продолжительности жизни, увеличению рождаемости, снижению младенческой смертности, то есть данные проявления будет заметны не сразу, а как минимум через несколько лет [5, с. 10];

- при увеличении расходов бюджета на социальное обеспечение населения на 1 млн тенге, увеличение ВВП составит 0,01 млрд тенге.

Полученные результаты свидетельствует о возрастающей роли затрат бюджета на развитие человеческого капитала в формировании ВВП. Жители Республики Казахстан пользуются предложенными государством благами, работают на территории страны, развивают свой человеческий капитал и способствуют приросту ВВП.

При помощи корреляционного анализа рассмотрим эконометрическую модель, описывающую зависимость ВВП от исполнения затрат государственного бюджета Республики Казахстан по расходам, связанным с развитием государственного управления.

Результативный показатель: У - величина ВВП Республики Казахстан, млрд тг.

Факторы, зависящие от результативного показателя:

X1 - расходы на оборону, млн тг.

X2 - расходы на поддержание общественного порядка, безопасности, млн тг.

Х3 - расходы на государственные услуги общего характера, млн тг.

Параметры множественной регрессии приведены в таблице 2.

\section{Параметры множественной регрессии *}

\begin{tabular}{|c|r|r|r|r|r|r|r|}
\hline Показатель & 2013 г & 2014 г & $2015 \Gamma$ & 2016 г & $2017 \Gamma$ & 2018 г & 2019 г \\
\hline $\mathrm{V}$ & 35999 & 39676 & 40884 & 46971 & 54378 & 61819 & 64600 \\
\hline $\mathrm{X} 1$ & 396512 & 431664 & 453682 & 438499 & 452375 & 542129 & 623448 \\
\hline $\mathrm{X} 2$ & 608346 & 601048 & 557439 & 584170 & 709712 & 795090 & 898452 \\
\hline $\mathrm{X} 3$ & 382136 & 483663 & 697302 & 622484 & 652254 & 611026 & 641577 \\
* Составлена автором по [6]
\end{tabular}

Расчеты производим с помощью программы Stata14.

В результате расчетов было получено уравнение множественной регрессии:

$$
\mathrm{y}=-0,04 \mathrm{x} 1+0,09 \times 2+0,04 \times 3
$$

Следовательно, в рассматриваемой нами модели наибольшее влияние на результативный показатель (У) оказывает фактор X2 - расходы на поддержание безопасности. С ростом расходов на поддержание безопасности на 1 млн тенге объем ВВП возрастет на 0,09 млрд тенге.

Экономическая интерпретация модели:

- увеличение расходов на оборону на 1 млн тенге приводит к уменышению ВВП на 0,04 млрд тенге. Такую тенденцию можно объяснить перетя- гиванием ресурсов из других отраслей экономики; - рост расходов на государственные услуги общего характера на 1 млн. тенге способствует увеличению объема ВВП на 0,04 млрд тенге.

Далее нам осталось рассмотреть при помощи корреляционного анализа эконометрическую модель, описывающую зависимость ВВП от затрат бюджета на стимулирование отраслей экономики в сфере инноваций.

Результативный показатель: У - величина ВВП Республики Казахстан, млрд тг. Факторы, зависящие от результативного показателя:

X1 - расходы на топливно-энергетический комплекс и недропользование, млн тенге;

Х2 - расходы на сельское, лесное, водное, рыбное хозяйство, особоохраняемые природные 
Каржсы және есеп / Финансы и учет

территории, охрана окружающей среды и животного мира, земельные отношения, млн тенге;

Х3 - расходы на промышленность, строи- тельство, архитектура, млн тенге;

X4 - расходы на транспорт и коммуникации, млн тенге.

Параметры множественной регрессии*

\begin{tabular}{|c|r|r|r|r|r|r|r|}
\hline Показатель & 2013 г & \multicolumn{1}{|c|}{2014 г } & \multicolumn{1}{|c|}{2015 г } & \multicolumn{1}{|c|}{2016 г } & \multicolumn{1}{|c|}{2017 г } & \multicolumn{1}{|c|}{2018 г } & \multicolumn{1}{c|}{2019 г } \\
\hline $\mathrm{V}$ & 35999 & 39676 & 40884 & 46971 & 54378 & 61819 & 64600 \\
\hline $\mathrm{X} 1$ & 119606 & 128656 & 111533 & 100423 & 137939 & 130489 & 135699 \\
\hline $\mathrm{X} 2$ & 258839 & 349079 & 376038 & 414528 & 474307 & 501835 & 526927 \\
\hline $\mathrm{X} 3$ & 32188 & 42538 & 61775 & 46324 & 29791 & 35860 & 39446 \\
\hline $\mathrm{X} 4$ & 511366 & 614202 & 681697 & 761990 & 850434 & 834187 & 875896 \\
\hline
\end{tabular}

Таблица 3 Stata14

Расчеты проведены с помощью программы

В результате расчетов было получено уравнение множественной регрессии:

$$
y=0,12 \times 1+0,23 \times 2+0,29 \times 3+0,08 \times 4
$$

Экономическая интерпретация модели имеет вид:

- увеличение расходов на инновационное развитие топливно-энергетического комплекса и недропользования на 1 млн тенге приведет к росту ВВП на 0,12 млрд тенге;

- увеличение расходов на инновационное развитие сельского, лесного, водного, рыбного хозяйства на 1 млн тенге способствует росту ВВП на 0,23 млрд тенге;

- увеличение расходов на инновационное развитие промышленности, строительства, архитектуры на 1 млн тенге приведет к росту ВВП на 0,29 млрд тенге;

- увеличение расходов на инновационное развитие транспорта и коммуникаций на 1 млн тенге вызовет увеличение ВВП на 0,08 млрд тенге.

Полученные результаты свидетельствует о возрастающей роли затрат бюджета на инновационное развитие отраслей экономики и на развитие человеческого капитала.

Эффективное управление бюджетными ресурсами Республики Казахстан затрудняется из-за большого количества программ, ответственность за реализацию которых возложена на различные государственные органы.

Для повышения эффективности государственных финансов предлагаем использовать целостную систему открытости деятельности государственных органов на базе информаци- онной системы управления общественными финансами «Электронный бюджет».

Являясь составной частью электронной модели государственного управления, система «Электронный бюджет» способствует реализации следующих задач:

- достичь повышения качества и эффективности государственного управления бюджетными средствами;

- обеспечить открытость деятельности государственных органов, в том числе самого процесса этой деятельности.

Применение системы «Электронный бюджет» позволят достичь следующего эффекта:

- повышение достоверности учета обязательств и скорости формирования отчетности;

- прекращение постоянной сверки информации между органами казначейства и бюджетополучателями;

- обеспечение прозрачности бюджетных расходов и создание системы непрерывного автоматического казначейского контроля на всех этапах исполнения бюджета.

Заключение. Нами проведен корреля ционный анализ зависимости ВВП от исполнения затрат государственного бюджета Республики Казахстан по расходам, сгруппированным по следующим сферам деятельности государства: расходы на развитие человеческого капитала, расходы на инновационное стимулирование экономики, расходы на управление государством. Корреляционный анализ в рамках трех разработанных моделей был осуществлен при помощи программы Stata14.

Результаты корреляционной модели, описывающей влияние зависимости ВВП от расходов 


\section{Қаржы жсәне есеп / Финансы и учет}

на инновационное стимулирование экономики, свидетельствует о возрастающей роли затрат бюджета на инновационное развитие отраслей экономики и на развитие человеческого капитала.

Рекомендуемое авторами применение системы «Электронный бюджет» способствует по- вышению эффективности бюджетного процесса благодаря повышению производительности труда работников, занятых в сфере управления государственными финансами, в связи с сокращением операционных расходов.

\section{ЛИТЕРАТУРА}

1. Искакова 3.Д. Теоретические основы финансов, кредита и роль финансовой системы в развитии Стратегии Казахстана. - Алматы, 2014. - 254 с.

2. Сабирова Р.К., Косаев Д. Куанышев У. Проблемы государственного бюджета Республики Казахстан // Большая Евразия: развитие, безопасность, сотрудничество. - 2019. - №3 . - С.23-26.

3. Сухарев А.С. Бюджетные расходы, эффективность и приоритеты развития экономики // Финансовый журнал. - 2015. - №1 (23). - С. 21-27.

4. Бишимбаев В. Инновационный вектор Казахстана // Казахстанская правда. - 2015. - 13 июня. - http://www.kazpravda.kz/rubric/ mir/proriv-k-innovatsionnomu-budushchemu/

5. Кудрин А., Кнобель А. Бюджетная политика как источник экономического роста // Вопросы экономики. - №10. - Октябрь 2017. - С. 5-26.

6. Отчет Счетного комитета по исполнению республиканского бюджета за 2019 год // http:// www.esep.gov.kz.

\section{REFERENCES}

1. Iskakova Z.D. Teoreticheskieosnovyfinansov, kredita i rol' finansovojsistemy v razvitii Strategii Kazahstana. - Almaty, 2014. - 254 s. [in Russian].

2. Sabirova R.K., Kosaev D. KuanyshevU. Problemy gosudarstvennogo bjudzheta Respubliki Kazahstan// Bol'shaja Evrazija: razvitie, bezopasnost', sotrudnichestvo. - 2019. - №3. - S. 23-26 [in Russian].

3. Suharev A.S. Bjudzhetnye rashody, jeffektivnost' i prioritety razvitijaj ekonomiki // Finansovy jzhurnal. - 2015. - №1 (23). - S. 21-27 [in Russian].

4. Bishimbaev V. Innovacionnyj vektor Kazahstana // Kazahstanskaja pravda. - 2015. - 13 ijunja. http://www.kazpravda.kz/rubric/ mir/proriv-k-innovatsionnomu-budushchemu/ [in Russian]

5. Kudrin A., Knobel' A. Bjudzhetnaja politika kak istochnik jekonomicheskogo rosta // Voprosyj ekonomiki. - №10. - Oktjabr' 2017. - C. 5-26 [in Russian].

6. Otchet Schetnogo komiteta po ispolneniju respublikanskogo bjudzheta za 2019 god // http:// www.esep.gov.kz [in Russian].

\section{К.Ә. Кененова}

\section{БЮДЖЕТТІК МЕНЕДЖМЕНТТІН ТИІМДІ ӘДІСТЕМЕСІН ЖАСАУ}

\section{Андатпа}

Мемлекеттің қаржылық-бюджеттік саясатын іске асырудың мақсаты-әлеуметтік-экономикалық даму, елдің қауіпсіздігін қамтамасыз ету, халықтың әл-ауқатын арттыру. Бұл мақалада қызмет саласына байланысты келесі топтарға бюджет шығыстарын жиынтық бөлу әдістемесі қарастырылған: адами капиталды дамыту, экономиканы инновациялық ынталандыру және мемлекеттік басқару шығындары. Мұндай әсерді сандық зерттеу үшін біз жоғарыда қарастырылған топтардың әрқайсысының ЖІӨ-ге шығындарының әсерін қарастыратын бірнеше регрессияның үш моделін жасадық. Эконометрикалық модельдеуді жүргізу құралы ретінде Stata14 бағдарламасы пайдаланылды. Алынған нәтижелер ЖІӨ-нің қалыптасуында адами капиталды дамытуға бюджеттік шығыстардың рөлінің артып келе жатқанын көрсетеді.

Мемлекеттік қаржыны пайдаланудың тиімділігін арттыру мақсатында қоғамдық қаржыны басқарудың ақпараттық жүйесі болып табылатын "электрондық бюджет" негізінде мемлекеттік органдар қызметінің ашықтығының тұтас жүйесінде пайдалануды ұсынамыз, оны пайдалану бухгалтерлік есептің сенімділігін арттырады, міндеттемелер мен есеп беру жылдамдығы үшін, қазынашылық органдары мен 


\section{Каржыл жеәне есеп / Финансы и учет}

бюджетті алушылардың арасында жүргізіліп жатқан мәліметтерді салыстыруды тоқтату, бюджет шығыстарының ашықтығын қамтамасыз етеді және бюджетті атқарудың барлық кезеңдерінде үздіксіз автоматты қазынашылық бақылау жүйесін жасайды.

\section{K. Kenenova}

\section{DEVELOPMENT OF AN EFFECTIVE METHODOLOGY FOR BUDGET MANAGEMENT}

\section{Annotation}

The implementation of the financial and budgetary policy of the state has the goal of social and economic development, ensuring the country's security, improving the well-being of the population. This article examines the methodology for the aggregated distribution of budget expenditures into the following groups, depending on the field of activity: expenditures on the development of human capital, on innovation stimulation of the economy, on government management. To quantitatively study this effect, we have compiled three multiple regression models that consider the impact on GDP of expenditures of each of the groups considered above. The data for the calculation are the statistical data of the Republic of Kazakhstan for 2013-2019. The Stata14 program was used as a tool for carrying out econometric modeling. The results obtained indicate the growing role of budget expenditures on the development of human capital in the formation of GDP. To increase the efficiency of the use of public finances, we propose to use an integral system of openness of the activities of state bodies based on the information system for managing public finances "Electronic Budget", the use of which will increase the reliability of accounting for obligations and the speed of reporting; stop the ongoing reconciliation of information between treasury authorities and budget recipients; will ensure transparency of budget expenditures and create a system of continuous automatic treasury control at all stages of budget execution.



